\title{
Molecular cytogenetic analysis of the karyotype of the European Atlantic sturgeon, Acipenser sturio
}

\author{
JAMES TAGLIAVINI†, PATRICK WILLIOT $\div$, LEONARDO CONGIU§, MILVIA CHICCA§, \\ MASSIMO LANFREDI§, REMIGIO ROSSI§ \& FRANCESCO FONTANA*§ \\ $\dagger$ Department of Evolutionary Biology, University of Parma, Via delle Scienze, 43100 Parma, Italy, $\ddagger$ Cemagref, \\ Division Aquaculture et Pêche, BP 3, 33612 Cestas, France and §Department of Biology, University of Ferrara, \\ Via L. Borsari, 46, I-44100 Ferrara, Italy
}

\begin{abstract}
A karyotype analysis was carried out on the European Atlantic sturgeon, Acipenser sturio $(2 n=121 \pm 3)$. The telomeric sequence repeat (TTAGGG) $)_{n}$ detected by fluorescent in situ hybridization (FISH) was mostly localized at the telomeres of all chromosomes. Ribosomal DNA (rDNA) genes were detected by silver staining techniques and by FISH with digoxigenin-labelled probe for $28 \mathrm{~S}$ rDNA. Silver staining detected active NORs in the telomeric regions of six chromosomes, and by FISH one or two additional minor sites were detected. The 5S rDNA was found in the interstitial region of a small metacentric pair. The 5S rRNA gene was completely sequenced for the first time in a sturgeon species. The A. sturio karyotype organization is discussed in relation to phylogenesis of the species within the Acipenseridae and to polyploidization events characterizing sturgeon evolution.
\end{abstract}

Keywords: $28 \mathrm{~S}$ and 5S rDNA, Acipenser, FISH, karyotype, sturgeon, telomeric sequence.

\section{Introduction}

The European Atlantic sturgeon, Acipenser sturio, is an anadromous fish. It was commonly found in most European river basins until the middle of the century (Magnin, 1962). After the 1960s, increased fishing, combined with the environmental impact of dams, resulted in rapid numerical decrease of the species. Only two relict populations are known today: one inhabits the Gironde estuary system (with its tributary rivers, Garonne and Dordogne) and the other populates the Black Sea (the Rioni River basin in Georgia) (Williot et al., 1997). In many European countries, A. sturio is considered an endangered species and consequently it is protected. Birstein \& DeSalle (1998), on the basis of molecular data supporting previous palaeontological findings by Russian authors (cited in Birstein \& DeSalle, 1998), consider A. sturio as the most primitive species within the genus Acipenser, whose origin has been traced back to the Upper Cretaceous. A detailed knowledge of A. sturio cytogenetics could therefore provide relevant data to clarify the evolution and phylogeny of this sturgeon species in comparison to the others.

*Correspondence. E-mail: fon@dns.unife.it
The karyotype of the Acipenseridae is characterized by a very high number of chromosomes, about half of which are microchromosomes. The sturgeons may be karyotypically divided into two groups, one with approximately 120 chromosomes and the other with 240-260 (see Fontana, 1994 and Birstein et al., 1997 for a summary). The karyotype of the European Atlantic sturgeon $(2 n=116 \pm 4)$, first described by Fontana \& Colombo (1974), belongs to the 120-chromosome group. Since then, no other karyological data have been reported for this species.

To investigate the karyotype organization of A. sturio further, we used fluorescent in situ hybridization (FISH) to localize the telomeric sequence (TTAGGG) $n$ and to identify the number and position of $28 \mathrm{~S}$ and $5 \mathrm{~S}$ rDNA clusters. The active nucleolar organizer regions (NORs) were detected by silver staining. The results are discussed in relation to European Atlantic sturgeon phylogenesis within the Acipenseridae and polyploidization events which occurred during sturgeon evolution.

\section{Materials and methods}

Three A. sturio individuals were sampled from the Gironde estuarine population. Chromosome preparations 
were made from fibroblast fin culture using the technique described by Fontana et al. (1997). Active NORs were visualized with colloidal silver staining (Howell \& Black, 1980).

For localization of telomeric sequences, in situ hybridization with a digoxigenin-labelled deoxynucleotide (TTAGGG) $)_{n}$ was performed following the manufacturer's suggestion (Oncor, Gaithersburg, MD).

Ribosomal probes for FISH analysis were derived from genomic DNA of $A$. naccarii. The $28 \mathrm{~S}$ rDNA probe was composed of two different fragments (approximately 400-bp and 700-bp long) of the coding region. The $5 \mathrm{~S}$ rDNA probe was a fragment about 230-bp long including both the gene and a nontranscribed (NTS) sequence. The fragments were obtained by standard PCR using the following primers: (i) universal 28S 'D1F and D1R' (Zardoya \& Meyer, 1996) for the first 400-bp fragment; (ii) L28S (5'-TCCGACCCGTCTTGAAACACGG-3') and R28S (5'-TTGATTCGGCAGGTGAGTTGTTACACC-3') for the second 700-bp fragment, designed from the A. brevirostrum 28S rDNA sequence ABU34340; and (iii) $5 \mathrm{SF}$ (5'-TACGCCCGATCTCGTCCGATC-3') (Pendás et al., 1994) and 5SR (5'-CAGGCTGGTATGGCCGTAAGC-3'). The fragments were cloned in pMOS-blue vector (Amersham Pharmacia Biotech Inc., Cleveland, $\mathrm{OH}$ ) and the clones employed as a source of DNA for probe synthesis. The clones were characterized by sequencing with Thermo Sequenase radiolabelled terminator cycle sequencing kit (Amersham Pharmacia Biotech, Inc., Cleveland, $\mathrm{OH}$ ).

The complete sequence of the 5S rDNA gene was obtained as follows. The fragment used as a probe (clone pMOS5SN8) was sequenced and two new primers were designed from it: NTSF (5'-ACAATTGAAATGTGTGGAGGA-3') which anneals to a sturgeon-specific 5S nontranscribed spacer sequence, and NTSR (5'CAGCACTTGATATTCCCAGG-3') which anneals to a conserved gene region (Fig. 1). The fragment obtained by these two primers from $A$. sturio genomic DNA was

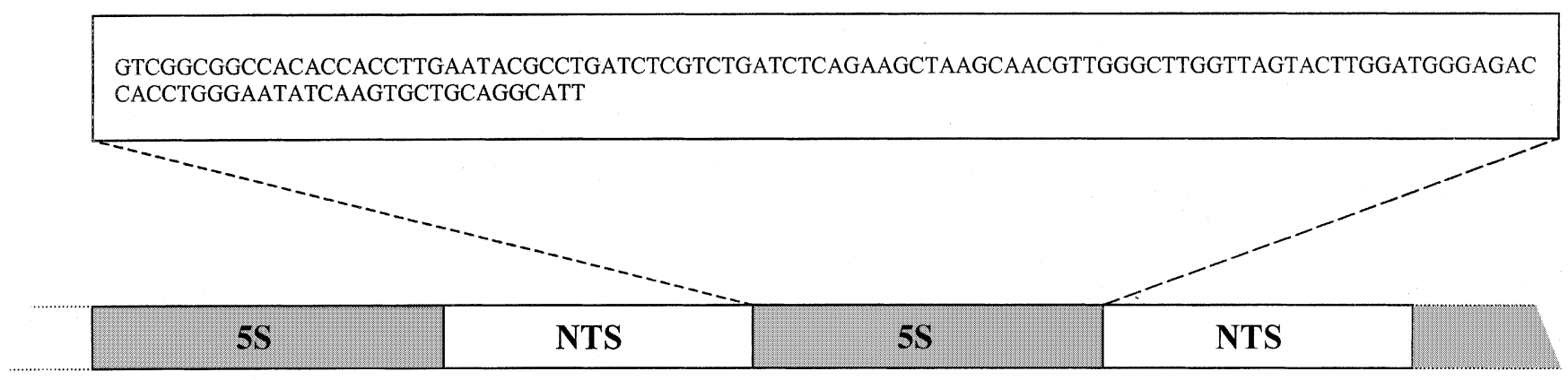

Primer 5SF $\underset{A}{\longrightarrow} \sim 230 \mathrm{bp} \quad \longrightarrow$ Primer 5SR

Primer 5NTSF $\longleftrightarrow \quad$ B $\quad 200 \mathrm{bp} \quad \longleftarrow$ Primer 5NTSR

\begin{abstract}
(A) pMOS5SN8-tacgccegatctcgtccgatc TCAGAAGCTAAGCAACGTTGGGCTTGGTTAGTACTTGGATGGGAGACCACCTGGGAATATCA (A) AGTGCTGCAGGCATTACATTTTTGTAATTACATTTTACAATTGAAATGTGTGGAGGACAAAATGAAATCTCGGGGGAATCACCCCCAGCTCAC

(B)

(A) CGAACAGAAAAGTCATAAAAGCAGAACTGCAACCgcttacggccataccagcetg

(B) CGAACAGAAAAGTCATAAARGCAGAACTGCAAYCGTCGGCGGCCACACCACCTTGAATACGCCTGATCTCGTCGATCTCAGAAGCTAAGCAAC

(B) GTTGGGCTTGGTTAGTACTTGGATGGGAGACCAcctgggaatatcaagtgctg - (<-NTSR)
\end{abstract}

Fig. 1 Diagram of the 5S rDNA cluster in Acipenser sturio and location of primers used for PCR amplification and sequencing (5SF-5SR and NTSF-NTSR). Fragment A was used as the 5S probe for in situ hybridization. Alignment of fragments A and B yielded the complete 221-bp sequence of the 5S gene. Primer sequences (or their complementary sequences) are reported in lower case.

(C) The Genetical Society of Great Britain, Heredity, 83, 520-525. 


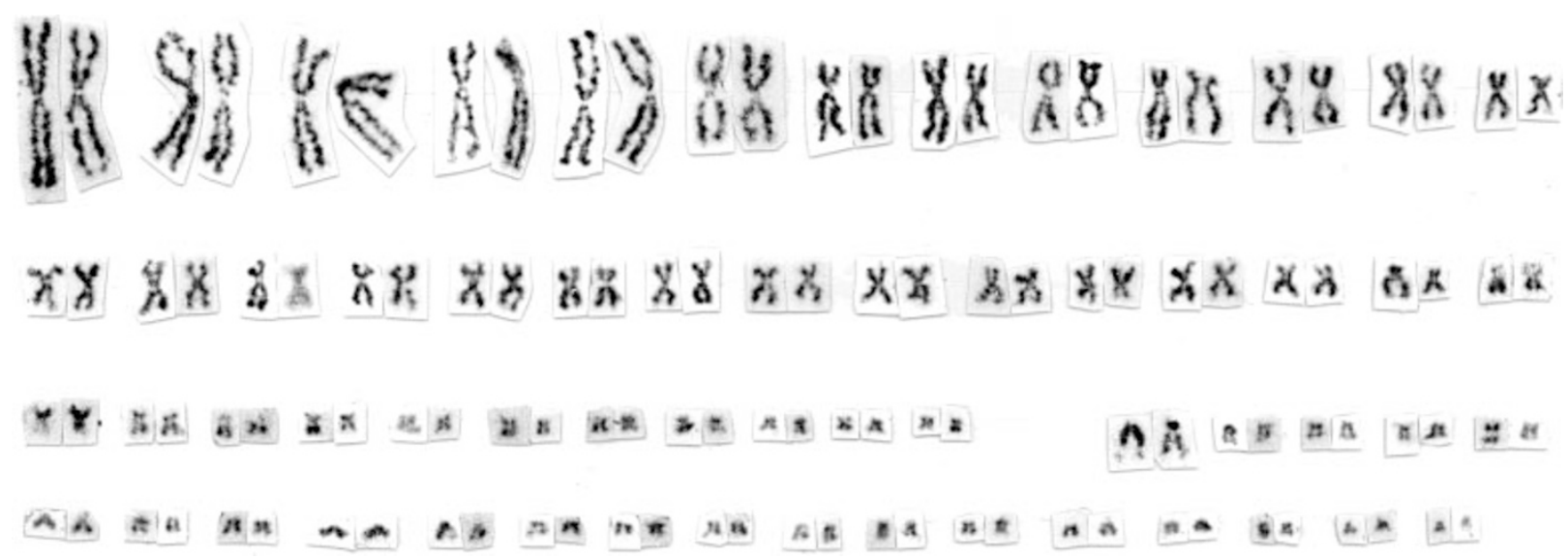

Fig. 2 Karyotype of Acipenser sturio $(2 n=120)$. The meta- and submetacentric chromosomes are aligned in order of decreasing size, followed by acrocentrics and microchromosomes $(\times 1056)$.

directly sequenced. Both $5 \mathrm{SF}-5 \mathrm{SR}$ and NTSF-NTSR sequences were combined to yield the complete sequence of 5S rDNA gene, for the first time in sturgeons (Fig. 1).

Probes were digoxigenin-labelled by PCR DIG probe Synthesis Kit (Boehringer Mannheim, Germany) according to the manufacturer's specification. The two $28 \mathrm{~S}$ probes were used simultaneously, but separately from the $5 \mathrm{~S}$ probe. Prior to in situ hybridization, metaphase spreads were treated with RNase and pepsin, denatured with formamide ( $70 \%$ in $2 \times \mathrm{SSC}$ for $2 \mathrm{~min}$ at $72^{\circ} \mathrm{C}$ ), followed by dehydration in an ethanol series at $-20^{\circ} \mathrm{C}$, and air-dried. The hybridization solution $(10 \%$ dextrane sulphate, $60 \%$ formamide in $2 \times \mathrm{SSC}, 150 \mathrm{ng}$ digoxigenated probe, total volume $35 \mu \mathrm{L}$ ) was denatured for $10 \mathrm{~min}$ at $74^{\circ} \mathrm{C}$, then the slides were transferred to a wet chamber for overnight hybridization at $37^{\circ} \mathrm{C}$. The slides were then washed three times $(5 \mathrm{~min}$ each) in $60 \%$ formamide and $2 \times \mathrm{SSC}$ at $37^{\circ} \mathrm{C}$ and rinsed twice $(5 \mathrm{~min}$ each) in $4 \times$ SSC plus $0.1 \%$ Tween 20 . Detection was carried out at $37^{\circ} \mathrm{C}$ with fluorescent Antibody Enhancer Set (Boehringer, Mannheim, Germany). The chromosomes were counterstained with propidium iodide. Observations were made with a Leitz Orthoplan epifluorescent microscope with appropriate filter combinations. Photographs were recorded with a 400 ASA colour slide film (Kodak Ektachrome).

\section{Results}

The chromosome number of $A$. sturio, resulting from the analysis of 40 metaphases from three individuals, was $2 n=121 \pm 3$. A karyotype reconstruction is shown in Fig. 2. It consists of 39 pairs of meta-submetacentrics, 21 pairs of acrocentrics and microchromosomes. The chromosomes are arranged in decreasing size. In this metaphase the fundamental number (number of chromosome arms) is therefore 198.

The telomeric signals, detected by FISH as definite spots in Fig. 3(a), were located at the ends of each chromosome arm. Because the periphery of the plate is slightly out of focus, a few chromosomes show weaker or no signals. However, these signals were detected in another 16 metaphase plates when chromosomes were in the centre of the plate. Some other chromosomes apparently show interstitial signals but these are caused by chance end-to-end association. No interstitial signal was consistently observed in different metaphase plates.

The modal number of active NORs, as detected on 14 metaphases after silver-staining, was six. This was also the maximum number of NORs observed. The NORs were located in the telomeric region of one arm in each of six medium size meta- or submetacentric chromosomes (Fig. 3b). In situ hybridization with the $28 \mathrm{~S}$ rDNA probes also revealed clear signals of different intensities interspersed within the telomeric regions of six chromosomes (Fig. 3c). Additional sites of weak hybridization were also detected on one or two small chromosomes. After hybridization with the $5 \mathrm{~S}$ probe, two very intense fluorescent signals were observed in the mid region of a pair of small chromosomes (Fig. 3d).

The sequencing of the PCR fragment obtained using primers 5NTSR and 5NTSF allowed us to obtain the complete sequence of the 5S rRNA gene for the first time in a sturgeon species (Fig. 1). The 5S rDNA probe sequence (clone pMOS5SN8) includes an entire NTS and part of the transcribed gene. The latter shows high similarity with known vertebrate $5 \mathrm{~S}$ gene sequences. Preliminary data on 5S rDNA gene sequences in other sturgeon species show almost complete identity (data not shown). 

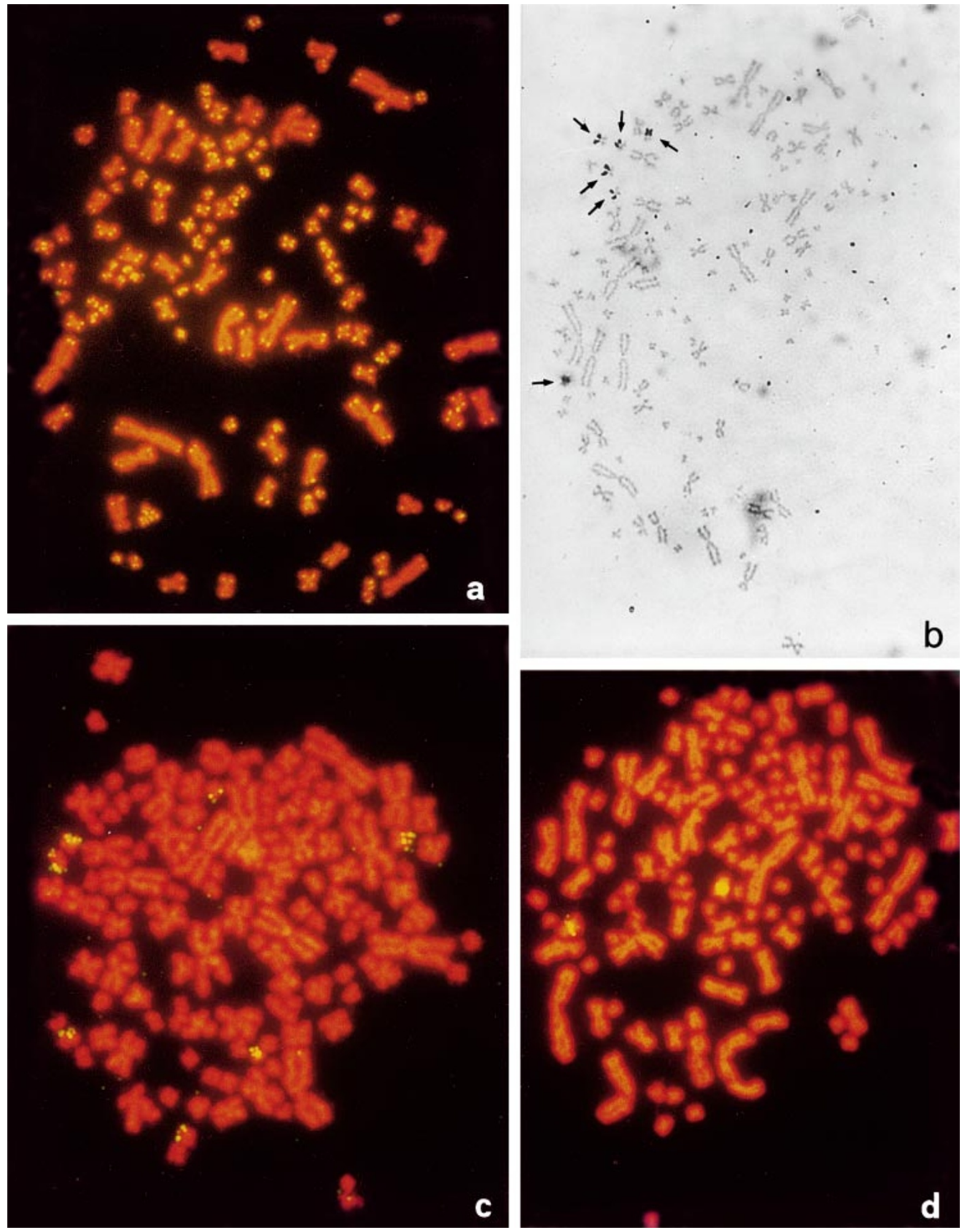

Fig. 3 Metaphases of Acipenser sturio: (a) FISH with biotin-labelled (TTAGGG) ${ }_{n}$ oligomers, counterstained with propidium iodide; (b) silver-staining showing NORs (arrows); (c) FISH of the 28S rDNA probe detected with digoxigenin and counterstained with propidium iodide; (d) FISH of the 5 S rDNA probe detected with digoxigenin and counterstained with propidium iodide (a: $\times 853$; b: $\times 864$; c: $\times 1173$; d: $\times 960$ ). 


\section{Discussion}

The observed chromosome number of $A$. sturio is $2 n=121 \pm 3$, different from $2 n=116 \pm 4$ previously reported by Fontana \& Colombo (1974). Furthermore, each morphological group in which the karyotype is divided shows a different number of chromosome pairs from that previously reported. This is because of the improved karyotype resolution afforded by cell culture techniques which allows a more precise count and a better identification of chromosome morphology. Actually, some chromosomes previously considered as acrocrocentrics and microchromosomes (Fontana \& Colombo, 1974) revealed themselves, respectively, as subtelocentrics and acrocentrics.

The telomeric sequence repeat (TTAGGG) ${ }_{n}$ detected by FISH was present in all telomeric regions. A similar pattern of signal distribution was observed in A. naccarii, A. ruthenus and A. baeri (Fontana et al., 1998a). The absence of interstitial telomeric signals suggests that no recent chromosome rearrangements have occurred in these species. However, in A. gueldenstaedti the presence of two chromosomes entirely marked with blocks of telomeric repeat sequences suggests the occurrence of recent rearrangements (Fontana et al., 1998a).

Six NORs were detected by silver staining, and one or two additional minor 28S rDNA sites were detected by FISH. The consistent location of the additional signals at the ends of chromosomes and their presence on both chromatids indicate that they truly represent additional rDNA sites. The discrepancy observed between the NOR numbers detected by silver staining and by FISH is because the latter technique detects all $28 \mathrm{~S}$ rDNA sequences, regardless of their activity. The presence of inactive rDNA sequences has been recorded in Huso huso (Fontana et al., 1998b) and in other fish species (Pendás et al., 1993a,b; Gornung et al., 1997).

Our results also indicate that the rDNA hybridization signals are physically scattered in the regions at the ends of the chromosome arms, as previously observed in H. huso (Fontana et al., 1998b). However, because of the small size of the NOR-bearing chromosomes it is not possible to ascertain whether the rDNA genes are interspersed in euchromatic or heterochromatic regions. An interspersed localization of rDNA in heterochromatin has been reported in other fishes, such as the rainbow trout, the Atlantic salmon and the Antarctic ice fish (Pendás et al., 1993a,b; Ozouf-Costaz et al., 1996). This could be a common feature of fish chromosomes.

In $A$. sturio the localization of 5S rDNA genes by FISH in the interstitial region of a small chromosome pair is in contrast to observations in $H$. huso, where they are localized in telomeric regions (Fontana et al., 1998b). Few other data on 5S rDNA localization in fishes are available. Pendás et al. (1994) found by FISH that the $5 \mathrm{~S}$ and $28 \mathrm{~S}$ rDNA genes were located on the same chromosome pair in the Atlantic salmon, whereas Martinez et al. (1996) observed them on different chromosomes in the eel. A simultaneous FISH detection with differentially labelled $28 \mathrm{~S}$ and $5 \mathrm{~S}$ probes could probably help to clarify whether the two rDNA clusters are localized on the same chromosome. However, the complexity of the A. sturio karyotype has not yet allowed us to obtain satisfactory results from double hybridization.

Assuming that a single NOR pair in fish species represents the plesiomorphic (or primitive) condition and multiple NOR pairs the apomorphic (or derived) one (Amemiya \& Gold, 1988), the presence of six NOR chromosomes arranged in three pairs makes unlikely, at least from a cytogenetical point of view, the hypothesis by Birstein \& DeSalle (1998) that A. sturio could be closely related to primitive species within the genus Acipenser. Other 120-chromosome sturgeon species, such as $A$. ruthenus and $H$. huso should rather be considered more primitive, because they possess only two NOR chromosome pairs.

Because of the high NOR number, the high chromosome number and the large amount of nuclear DNA, some authors inferred that sturgeon species with 120 chromosomes were tetraploid (Dingerkus \& Howell, 1976; Birstein \& Vasiliev, 1987). However, tetraploidization is difficult to accept on the basis of our results, because in $A$. sturio the number of NOR-bearing chromosome pairs is three and the number of $5 \mathrm{~S}$ rDNA-bearing chromosome pairs is one. In our opinion, the NOR number is more likely to result from gene duplication and unequal crossing-over from an ancestral rDNA site. The diploid condition is also supported by the fact that other 120-chromosome species such as A. ruthenus (Fontana, 1994) and H. huso (Fontana et al., 1998b) show by silver staining four NOR chromosomes which can be grouped into two morphologically different pairs. On the other hand, in the 240-chromosome species such as $A$. naccarii the NOR chromosomes are arranged in quadruplets, making it likely that these are the tetraploid species (Fontana, 1994). It is also possible to advance the hypothesis that an event of tetraploidization of the 120-chromosome karyotype could have occurred (maybe from an original genome with 60 chromosomes), followed by functional diploidization of the ribosomal genes.

\section{Acknowledgements}

This work was supported by the 4th Triennial Plan 'Aquaculture in Seas and Lagoons' of the Italian 
Ministry of Agriculture, Food Resources and Forestry, and by research grants from the Italian Ministry of University and Research.

\section{References}

AMEMiYA, C. T. AND GOLD, J. R. 1988. Chromosomal NORs as taxonomic and systematic characters in North American cyprinid fishes. Genetica, 76, 81-90.

BIRSTEIN, V. J. AND DESALlE, R. 1998. Molecular phylogeny of Acipenserinae. Mol. Phylogenet. Evol., 9, 141-155.

BIRSTEIN, V. J. AND VASILIEV, V. P. 1987. Tetraploid-octoploid relationships and karyological evolution in the order Acipenseriformes (Pisces). Karyotypes, nucleoli, and nucleolus-organizer regions in four acipenserid species. Genetica, 72, 3-12.

BIRSTEIN, V. J., HANNER, R. AND DESALle, R. 1997. Phylogeny of the Acipenseriformes: cytogenetic and molecular approaches. Envir. Biol. Fish., 48, 127-155.

DINGERKUS, G. AND HOWELL, w. M. 1976. Karyotypic analysis and evidence of tetraploidy in the North American paddlefish, Polyodon spathula. Science, 194, 842-844.

FonTANA, F. 1994. Chromosomal nucleolar organizer regions in four sturgeon species as markers of karyotype evolution in Acipenseriformes (Pisces). Genome, 37, 888-892.

FONTANA, F. AND COLOMBO, G. 1974. The chromosomes of Italian sturgeons. Experientia, 30, 739-742.

FONTANA, F., ROSSI, R., LANFREDI, M., ARLATI, G. AND BRONZI, P. 1997. Cytogenetic characterization of cell lines from three sturgeon species. Caryologia, 50, 91-95.

FONTANA, F., LANFREDI, M., CHICCA, M., AIELLO, V. AND ROSSI, R. 1998a. Localization of the repetitive telomeric sequence $(\text { TTAGGG) })_{n}$ in four sturgeon species. Chromosome Res., 6 , 303-306.

FONTANA, F., TAGLIAVINI, J., CONGIU, L., LANFREDI, M., CHICCA, M., LAURENTE, C. AND ROSSI, R. 1998b. Karyotypic characterization of the great sturgeon, Huso huso, by different staining techniques and fluorescent in situ hybridization with 28S, 5S rDNA genes and telomeric sequences. Mar. Biol., 132, 495-501.
GORNUNG, E., GABRIELLI, I., CATAUDELLA, S. AND SOLA, L. 1997. $\mathrm{CMA}_{3}$-banding pattern and fluorescent in situ hybridization with ribosomal genes in zebrafish chromosomes. Chromosome Res., 5, 40-46.

HOWELL, W. W. AND BLACK, D. A. 1980. Controlled silver-staining of nucleolus organizer regions with a protective colloidal developer: a 1-step method. Experientia, 36, 1014-1015.

MAGNIN, E. 1962. Recherches sur la systématique et la biologie des Acipenséridés, Acipenser sturio L., Acipenser oxyrhynchus Mitchill et Acipenser fulvescens Raf. Ann. Stat. Cent. Hydrobiol. Appl., 9, 7-242.

MARTINEZ, J. L., MORAN, P., GARCIA-VAZQUEZ, E. AND PENDAS, A. M. 1996. Chromosomal localization of the major and 5S rRNA genes in the European eel (Anguilla anguilla). Cytogenet. Cell Genet., 73, 149-152.

OZOUF-COSTAZ, C., PISANO, E., BONILlO, C. AND WILliAMS, R. 1996. Ribosomal DNA location in the Antarctic fish Champsocephalus gunnari (Notothenioidei, Channichthyidae) using banding and fluorescence in situ hybridization. Chromosome Res., 4, 557-561.

PENDÁs, A. M., MORÁN, P. AND GARCIA-VAZQUEZ, E. $1993 \mathrm{a}$. Ribosomal RNA genes are interspersed throughout a heterochromatic chromosome arm in Atlantic salmon. Cytogenet. Cell Genet., 63, 128-130.

PENDÁs, A. M., MORÁN, P. AND GARCIA-VAZQueZ, E. 1993 b. Multi-chromosomal location of ribosomal RNA genes and heterochromatin association in brown trout. Chromosome Res., 1, 63-67.

PENDÁs, A. M., MORÁN, P., FREIJE, J. P. AND GARCIA-VAZQUEZ, E. 1994. Chromosomal mapping and nucleotide sequence of two tandem repeats of Atlantic salmon. Cytogenet. Cell Genet., 67, 31-36.

WILLIOT, P., ROCHARD, E., CASTELNAUD, G., ROUAULT, T., BRUN, R., LEPAGE, M. AND ELIE, P. 1997. Biological characteristics of European Atlantic sturgeon, Acipenser sturio, as the basis for a restoration program in France. Envir. Biol. Fish., 48, 359-372.

ZARDOYA, R. AND MEYER, A. 1996. Evolutionary relationships of the coelacanth, lungfishes, and tetrapods based on the $28 \mathrm{~S}$ ribosomal RNA gene. Proc. Natl. Acad. Sci. U.S.A., 93, 5449-5454. 